\title{
X-ray diffraction analysis of products sintered from isostatically pressed leaded bronze powders
}

\author{
Evgeny Ageev ${ }^{1}$ and Anton Pereverzev ${ }^{1, *}$ \\ ${ }^{1}$ Southwest State University, 305040 Kursk, Russian Federation
}

\begin{abstract}
This article presents a study of the phase composition of samples sintered from isostatically pressed leaded bronze electroerosion powders obtained in distilled water. It is identified that the main phases in the sintered sample are $\mathrm{Cu}, \mathrm{Zn}_{2} \mathrm{SnO}_{4}, \mathrm{~Pb}\left(\mathrm{Cu}_{2} \mathrm{O}_{2}\right), \mathrm{PbO}, \mathrm{Fe}_{3} \mathrm{O}_{4}$.
\end{abstract}

\section{Introduction}

Leaded bronze is widely used in different industries. Due to its excellent antifriction properties, lead bronze is widely used in the manufacture of machine parts operating in friction joints.

The widespread industrial use of leaded bronze leads to a large accumulation of leaded bronze scrap, which requires processing. Nowadays, there are many ways to recycle metal waste for its repeated use. Still, the existing methods have many disadvantages; among them are energy inefficiency and overcomplexity of the process.

The most promising method of processing leaded bronze scrap is electroerosion dispersion, which is eco-friendly and energy-efficient.

Carrying out the planned measures will allow to solve the problem of waste recycling and thereby reduce the final cost of the product.

The aim of the research was to carry out X-ray diffraction analysis of sintered samples sintered from isostatically pressed leaded bronze electroerosion powders obtained in distilled water.

\section{Materials and Methods}

In order to obtain nanodispersed powder by electroerosion dispersion utilizing an experimental piece of equipment [1], we used leaded bronze scrap of GOST 493-79 in the form of chips. The chips were loaded into a test vessel filled with a power fluid - distilled water. In the process we used the following electrical parameters of the equipment: pulserecurrence rate $-95 \ldots 105 \mathrm{~Hz}$, electrode voltage $-190 \ldots 200 \mathrm{~V}$, capacity of condensers $65,5 \mu \mathrm{F}$. As a result of the local action of short-term electrical discharges between the electrodes, the scrap material was destroyed and dispersed powder particles were produced.

\footnotetext{
*Corresponding author: chaser-93@yandex.ru
} 
To get compacted materials, we used an isostatic press EPSI CIP 400-200*1000Y (Fig.1).

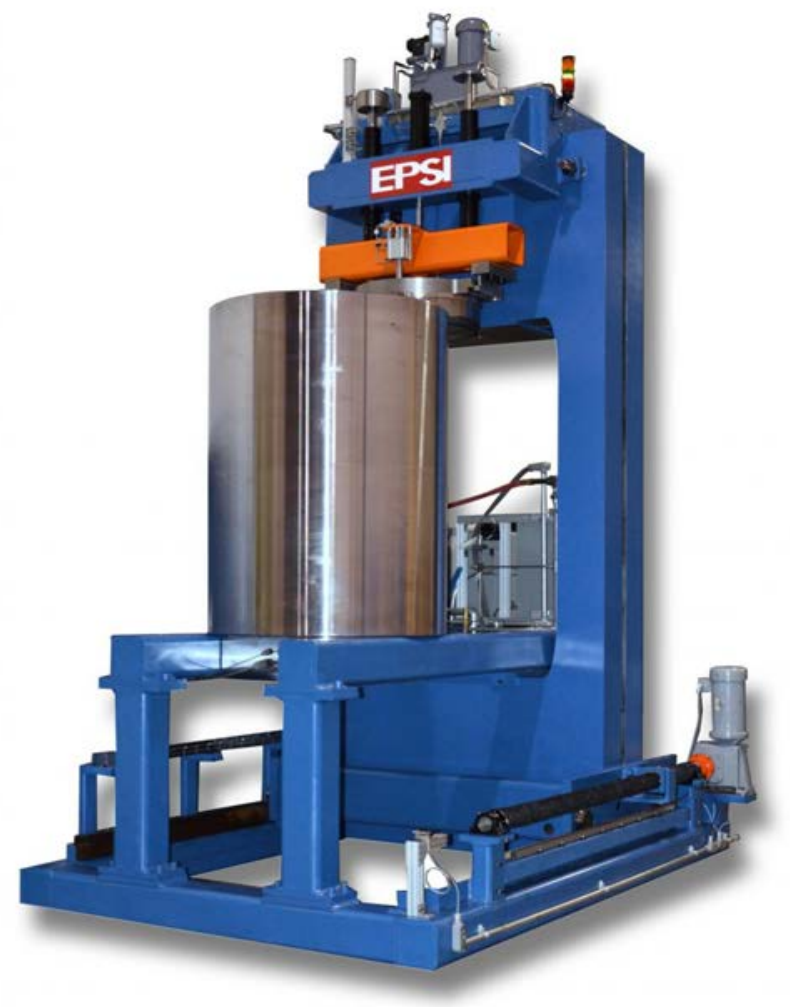

Fig. 1. Isostatic press EPSI CIP 400-200*1000Y

The operating principle of the isostatic press is to create a high hydrostatic pressure applied to the powder (metal or ceramic) at an ambient temperature. Water or oil is used as a pressure transmitter [2-3]. First, we put the powder in a rubber mold and then we manually compacted it up to a density of $3.1847 \mathrm{~g} / \mathrm{cm}^{3}$. Next, we put the sample in the press's process chamber at a temperature of $18{ }^{\circ} \mathrm{C}$ and injected the pressure to the prescribed rate. We maintained this pressure for 2 minutes, then we reduced it to atmospheric pressure and removed the sample from the form. The parameters we used during the isostatic pressing are: $250 \mathrm{MPa}, 30 \mathrm{~s}$.

After this, the obtained samples were sintered in a folding tube furnace Nabertherm RS 80/300/13 / P470 for 12 hours at a temperature of $827^{\circ} \mathrm{C}(1100 \mathrm{~K})$ in argon (Fig.2). 


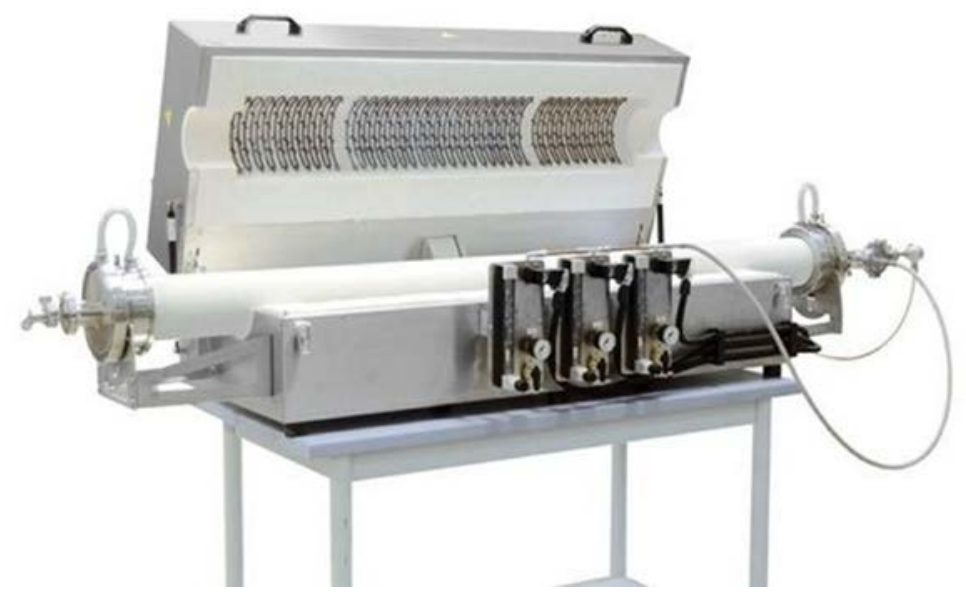

Fig. 2. Folding tube furnace Nabertherm RS 80/300/13/P470

The phase composition of the obtained sample was identified by X-ray diffraction on a diffractometer Rigaku Ultima IV in Cu-Ka radiation $(\lambda=0.154178 \mathrm{~nm})$ using Soller slits (Fig.3).

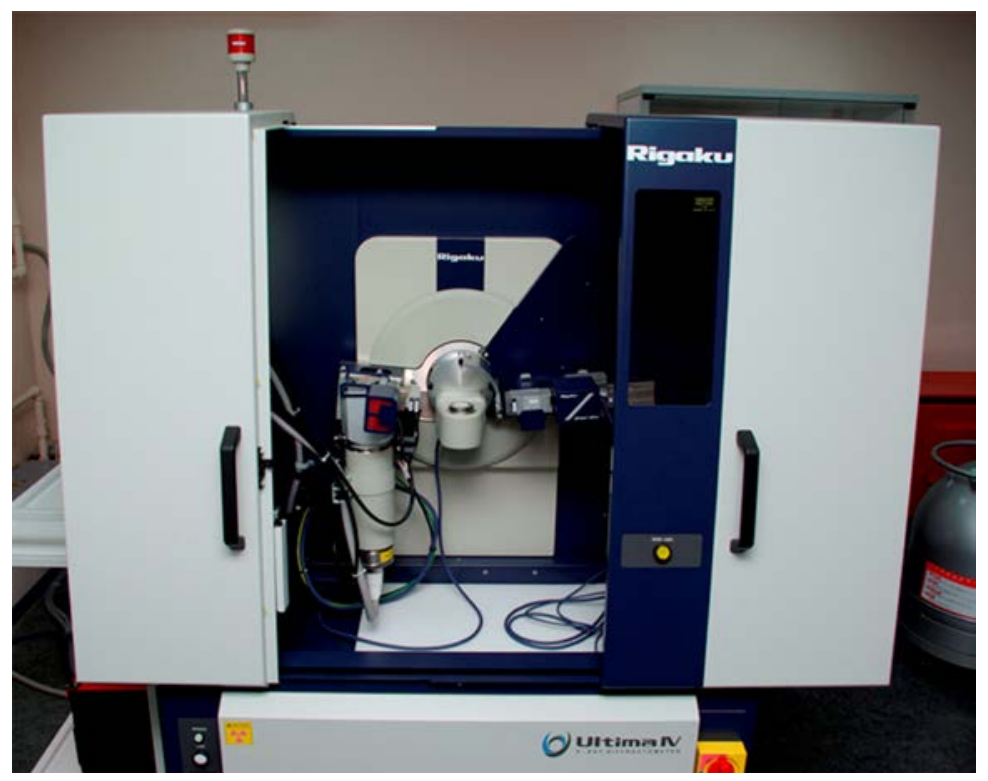

Fig. 3. X-ray diffractometer Rigaku Ultima IV

The software permits conduct a qualitative and quantitative phase analysis, a crystallinity analysis, an analysis of residual stresses and construct direct and inverse pole figures. Also it has a database of ICDD PDF-2 diffraction patterns and an orientation distribution function [4-6].

\section{Results}

The survey of the diffraction spectrum for the phase analysis is carried out according to the $\theta-2 \Theta$ scanning scheme using Bragg-Brentano focusing within the angle range of $5 \ldots 100$ 
degrees $(2 \Theta)$. The survey is undertaken in point-by-point mode with a scan step of 0.02 $\operatorname{deg}(\Delta(2 \theta)=0.02 \mathrm{deg})$, a speed of $0.6 \mathrm{deg} / \mathrm{min}$, an operating voltage of $45 \mathrm{kV}$ and a current of $200 \mathrm{~mA}$. To specify the profile of experimental X-ray patterns, the PDXL RIGAKU software package was used. The background differencing was made by the Sonneveld-Visser method, the experimental profile was smoothed by the Savitsky - Golaya method and the components $k \alpha 1$ and $k \alpha 2$ were separated by the Rachinger method. To describe the diffraction maximum, a superposition of the Gaussian and Lorentz functions was used. The approximation of each of the reflections in the diffraction patterns of the study samples by the pseudo-Voigt function allowed to accurately determine the position of the reflections taking into account the displacement, caused by overlapping of the reflexes, at half maximum intensity (FWHM) and the intensity [7-8]. The phase composition of the sapmles was identified using the ICCD PDF-2 database (2008).

The diffraction pattern and phase composition of the test sample are shown in Fig.4 and Table 1.

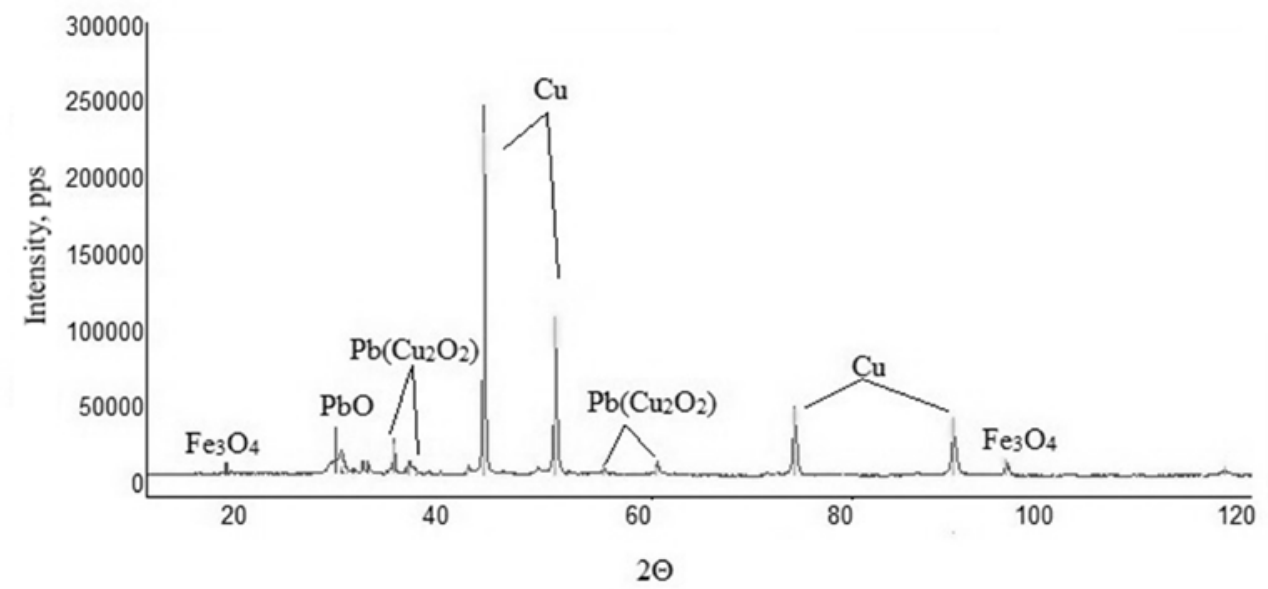

Fig. 4. Diffraction pattern of the study sample

Table 1. Phase composition of the study sample

\begin{tabular}{|c|c|c|}
\hline Chemical formula & Lattice type & Lattice examples \\
\hline $\mathrm{Cu}$ & $225: F m-3 m$ & $\mathrm{a}=3.611818 \mathrm{~A} ;$ \\
& cubic & $\mathrm{b}=3.611818 \mathrm{~A} ;$ \\
& & $\mathrm{c}=3.611818 \mathrm{~A}$ \\
\hline $\mathrm{Zn}_{2} \mathrm{SnO}_{4}$ & 227:Fd-3m,choice-2 & $\mathrm{a}=8.638801 \mathrm{~A} ;$ \\
& cubic & $\mathrm{b}=8.638801 \mathrm{~A} ;$ \\
& & $\mathrm{c}=8.638801 \mathrm{~A}$ \\
\hline $\mathrm{Pb}\left(\mathrm{Cu}_{2} \mathrm{O}_{2}\right)$ & $47:$ Pmmm & $\mathrm{a}=8.290755 \mathrm{~A} ;$ \\
& orthorhombic & $\mathrm{b}=8.358210 \mathrm{~A} ;$ \\
& & $\mathrm{c}=6.064729 \mathrm{~A}$ \\
\hline $\mathrm{PbO}$ & 129:P4/nmm,choice-2 & $\mathrm{a}=3.967405 \mathrm{~A} ;$ \\
& tetragonal & $\mathrm{b}=3.967405 \mathrm{~A} ;$ \\
& & $\mathrm{c}=5.028349 \mathrm{~A}$ \\
\hline $\mathrm{Fe}_{3} \mathrm{O}_{4}$ & $166: \mathrm{R}-3 m$, hexagonal & $\mathrm{a}=5.769619 \mathrm{~A} ;$ \\
& & $\mathrm{b}=5.769619 \mathrm{~A} ;$ \\
& & $\mathrm{c}=15.009869 \mathrm{~A}$ \\
\hline
\end{tabular}




\section{Conclusion}

Thanks to the conducted X-ray diffraction microanalysis, it was identified that the main phases in the isostatically pressed sintered sample obtained by electroerosion dispersion of leaded bronze scrap in distilled water are $\mathrm{Cu}, \mathrm{Zn}_{2} \mathrm{SnO}_{4}, \mathrm{~Pb}\left(\mathrm{Cu}_{2} \mathrm{O}_{2}\right), \mathrm{PbO}, \mathrm{Fe} 3 \mathrm{O}_{4}$. The conducted study will identify the most relevant area of the obtained material's application and will enhance the quality of scientific and technical developments.

The reported study was funded by RFBR, project number 19-38-90039.

\section{References}

1. E.V. Ageev, The patent 2449859, the Russian Federation, C2, B22F9/14. No 2010104316/02; appl. 08.02.2010; publ. 10.05.2012. - 4 p.

2. E. V. Ageev, B. A. Semenikhin, R. A. Latypov, Method for producing nanostructured powders based on the WC-CO system and device for its application, Fund. Prikl. Probl. Tekhn. Tekhnolog, v. 5, pp. 39-42 (2010)

3. Oskolkova T.N., Budovskikh E.A., Electric explosion alloying of the surface of hard alloy vk10ks with titanium and silicon carbide, Metal. Sci. Heat Treat, v. 55, pp. 96-99 (2013)

4. Karlsson J., Snis A., Engqvist H., Lausmaa J., Characterization and comparison of materials produced by Electron Beam Melting (EBM) of two different Ti-6Al-4V powder fractions, Journal of Materials Processing Technology, v. 213, pp. 2109-2118 (2013)

5. Gu D.D., Meiners W., Wissenbach K., Poprawe R., Laser additive manufacturing of metallic components: materials, processes and mechanisms, International Materials Reviews, v. 57, pp. 133-164 (2012)

6. N. Radek, Determining the operational properties of steel beaters after electrospark deposition, Maintenance and Reliability, v. 4, pp. 10-16 (2009)

7. A.V. Ribalko, O. Sahin, The use of bipolar current pulses in electro spark alloying of metal surfaces, Surface \& Coatings Technology, v. 168, pp. 129-135 (2003)

8. Z. Chen, Y. Zhou, Surface modification of resistance welding electrode by electrospark deposited composite coatings: Part I. Coating characterization., Surface \& Coatings Technology, v. 201, pp. 1503-1510 (2006)

9. I.V. Galinov, R.B. Luban, Mass transfer trends during electrospark alloying, Surface \& Coatings Technology. v. 79, pp. 9-18 (1996)

10. Azarova E.V., Levashov E.A., Ralchenko V.G., Creation of strong adhesive diamond coatings on hard alloy by electric-spark alloying, Translated from Metallurg. v. 8, pp. 50-55 (2010) 